\title{
Reabilitação em cães submetidos a artroplastia do joelho
}

\author{
Rehabilitation in dogs submitted to knee arthroplasty
}

\author{
Soraia Figueiredo de Souza ${ }^{1}$ Alexandre Mazzanti ${ }^{2}$ Alceu Gaspar Raiser ${ }^{2}$ \\ Fabiano Zanini Salbego ${ }^{1}$ Érika Toledo da Fonseca ${ }^{1}$ Rafael Festugatto $^{3}$ \\ Charles Pelizzari $^{1}$ Diego Vilibaldo Beckmann ${ }^{3}$ Lucilene Bernardi $^{3}$ \\ Rosmarine Passos ${ }^{3}$ Marina Mori da Cunha ${ }^{3}$
}

\section{RESUMO}

Com o objetivo de avaliar um protocolo de reabilitação em cães submetidos a homoimplante ortotópico tenopatelar conservado em glicerina a 98\%, seguido de imobilização rígida temporária da articulação do joelho, oito cães foram distribuídos em dois grupos de igual número, denominados I ou tratados e II ou controle. Após a remoção do aparelho de fixação externa biplanar, os cães do grupo I foram submetidos a terapia física durante 15 dias, que consistiu de hidroterapia, massageamento, movimentação passiva da articulação do joelho, alongamento passivo e exercícios de caminhada. Na avaliação clínica da articulação do joelho $e$ dos tecidos adjacentes, foi observado que os cães do grupo I apresentaram menores rigidez articular e contratura da musculatura da coxa em relação ao grupo II. Decorridos 90 dias de pós-operatório, foi observado que a amplitude de movimento foi maior em extensão no grupo tratado $(P<0,01)$. Quanto à avaliação clínica da marcha, foi verificado que os cães do grupo tratados $(n=4)$ atingiram o grau $V$ (uso funcional do membro), enquanto que, no grupo controle, somente um animal alcançou o mesmo grau. Pode-se concluir que o protocolo fisioterapêtico empregado promove o retorno funcional do membro operado quando comparado com o grupo não tratado. Recomenda-se o emprego da terapia física, compreendida de massagem, hidroterapia, movimentação passiva da articulação, alongamento passivo e exercícios de caminhada em cães submetidos à artroplastia do joelho e à imobilização rígida temporária da mesma articulação.

Palavras-chave: remobilização, imobilização, reabilitação articular.

\section{ABSTRACT}

The objective of this study was to evaluate the influence of a rehabilitation procedure in eight dogs undergone to arthroplasty followed by rigid immobilization of the knee joint. The dogs were alocated into a treated group (Group I) and a control group (Group II). After the removal of the biplanar external skeletal fixation device, the dogs from Group I were submitted to physical therapy during 15 days, that consisted of hydrotherapy, massage, passive movement of the knee joint, passive stretching and controlled walking exercises. The clinical evaluation of the knee and adjacent tissues of Group I showed less articular rigidity and thigh muscle contraction when compared with Group II. Ninety days after the operation, the evaluation of the range of motion demonstrated that the group of treated animals reached a greater extension $(P<0.01)$. As for the evaluation of the march, all of the treated animals $(n=4)$ reached a grade of $V$ (functional use of the member), whereas of the control group, only one animal reached the same grade. According to the results, it can be concluded that the physical therapy procedure used in the dogs from Group I promotes the functional rehabilitation of use of the limb earlier then in the dogs from the group control. Physical therapy can be recommended in dogs undergoing arthroplasty of the knee followed by temporary rigid immobilization of the same joint.

Key words: remobilization, immobilization, joint rehabilitation.

\section{INTRODUÇÃO}

A imobilização prolongada após cirurgia articular está associada a alterações na cartilagem, nos ligamentos, nos músculos e no complexo ossoligamento, gerando proliferação de tecido fibroso periarticular. A perda da mobilidade pode provocar dor, degeneração articular, diminuição da função e aumento

${ }^{1}$ Programa de Pós-graduação em Medicina Veterinária, Universidade Federal de Santa Maria (UFSM), Santa Maria, RS, Brasil. ${ }^{2}$ Departamento de Clínica de Pequenos Animais (DCPA), Centro de Ciências Rurais (CCR), UFSM, 97105-900, Santa Maria, RS, Brasil. E-mail: mazzal@smail.ufsm.br. Autor para correspondência.

${ }^{3}$ Curso de Medicina Veterinária, DCPA, CCR, UFSM, Santa Maria, RS, Brasil. 
no tempo de retorno funcional do membro operado (MARSOLAIS et al., 2002; CONZEMIUS, 2004). MAZZANTI et al. (2004) realizaram a imobilização externa rígida da articulação fêmoro-tíbio-patelar por um período de 30 dias após artroplastia do joelho, objetivando estabilização articular suficiente para reparação tecidual, e verificaram atrofia da musculatura da coxa, aderências e diminuição na amplitude articular. Os objetivos da reabilitação são promover adequada cicatrização, rápido retorno funcional do membro e prevenir complicações causadas pelo desuso como atrofia muscular e contratura articular (CLARK \& McLAUGHLIN, 2001; MARSOLAIS et al., 2002).

A massagem é um método terapêutico utilizado para aumentar o fluxo sangüíneo e linfático, reduzir o edema, liberar e alongar tendões, minimizar a cicatriz tecidual (TAYLOR, 1992) e produzir relaxamento muscular e analgesia (MILLIS \& LEVINE, 1997; DIGÓN, 2000; CLARK \& MCLAUGHLIN, 2001; SUTTON, 2004).

O alongamento passivo previne distensões musculares e libera movimentos articulares bloqueados ou enrijecidos (MAZZANTI et al., 2004). Quando em conjunto com exercícios de movimentação passiva da articulação, aumenta a flexibilidade das articulações e a extensibilidade dos tecidos periarticulares, dos músculos e dos tendões (MILLIS et al., 2004).

O presente trabalho, tem como objetivo avaliar a influência da fisioterapia na recuperação funcional do membro de cães submetidos à artroplastia do joelho seguida da imobilização rígida temporária.

\section{MATERIAL E MÉTODOS}

Neste experimento, que seguiu as normas do COBEA (Colégio Brasileiro de Experimentação Animal), foram utilizados oito cães provenientes do Biotério Central da UFSM, machos ou fêmeas, com peso entre 17 e $25 \mathrm{~kg}$. Os animais foram submetidos a exame clínico, vermifugados com pamoato de pirantel ${ }^{\mathrm{a}}$ (25mg kg-1 , via oral) e alojados em canis individuais por um período mínimo de 20 dias, para adaptação ao local. Foram distribuídos em dois grupos de igual número, denominados de grupo I ou tratados e grupo II ou controle.

Após realização da artroplastia do joelho por meio da técnica de homoimplante ortotópico tenopatelar (MAZZANTI et al., 2004), a articulação foi imobilizada por 30 dias numa angulação de $120^{\circ}$ por fixação externa percutânea biplanar com pinos de Steimann. No pós-operatório, os animais foram submetidos à terapia antiinflamatória com flunixin meglumine ${ }^{\mathrm{b}}\left(1,0 \mathrm{mg} \mathrm{kg}^{-1}\right)$ por via subcutânea (SC), uma vez ao dia, durante três dias, e cloridrato de tramadol ${ }^{\mathrm{c}}$ (2,0 $\left.\mathrm{mg} \mathrm{kg}^{-1}\right)$ por via intramuscular (IM), três vezes ao dia, durante dois dias. A limpeza das feridas cirúrgicas foi feita com solução fisiológica de $\mathrm{NaCl}$ a $0,9 \%$ e os pontos de pele foram removidos decorridos sete dias de pós-operatório.

Aos 30 dias de pós-operatório, os cães foram pré-medicados com sulfato de morfina ${ }^{\mathrm{d}}\left(0,5 \mathrm{mg} \mathrm{kg}^{-1}, \mathrm{SC}\right)$ e, no bloco cirúrgico, foram submetidos a anestesia geral de curta duração com propofole a $10 \%\left(5 \mathrm{mg} \mathrm{kg}^{-1}\right.$, via intravenosa) para a remoção do aparelho de fixação. Os animais permaneceram em repouso nos canis por 24 horas e, após isso, foram avaliados clinicamente em busca de alterações como dor à palpação, edema, crepitação e mobilidade da patela.

Decorridas 24 horas da remoção do fixador externo, os cães do grupo I ou tratados foram submetidos a terapia física, que consistiu de hidroterapia, massageamento por deslizamento superficial, movimentação passiva da articulação do joelho, alongamento passivo e exercícios de caminhada.

A hidroterapia da musculatura da coxa e da articulação do joelho operado consistiu da aplicação de duchas de água em baixa pressão (30pps) na temperatura de $37^{\circ} \mathrm{C}$, durante 15 minutos, uma vez ao dia, por 15 dias consecutivos e de forma concomitante com as outras modalidades terapêuticas (Figura 1).

Após cinco minutos de hidroterapia, foram realizados massageamento da musculatura da coxa por deslizamento superficial durante dois minutos, em sentido distal para proximal; movimentos passivos em flexão e extensão do joelho (15 ciclos) e alongamento passivo em flexão e extensão, com duração de 30 segundos em cada posicionamento. Os exercícios foram realizados de forma alternada entre si, totalizando um tempo de 10 minutos (Figura 2A).

Uma vez realizadas as sessões de hidroterapia, foram repetidos, com cada animal posicionado em decúbito lateral esquerdo, os mesmos exercícios terapêuticos supracitados por mais 10 minutos. Logo após, os animais foram submetidos, em um mesmo percurso, a exercício de caminhada com duração de 10 minutos, em piso macio e irregular (gramado), durante os 15 primeiros dias (Figura 2B). Depois, o exercício passou a ser efetuado em pisos mais consistentes (cimentado) e irregulares, por mais 15 dias. Além da caminhada, os animais foram soltos, avaliando-se a marcha sem a presença de guia. O tempo total da terapia física foi de 35 minutos, sendo 15 durante e 20 após a hidroterapia (Figuras 2A e 2B). 


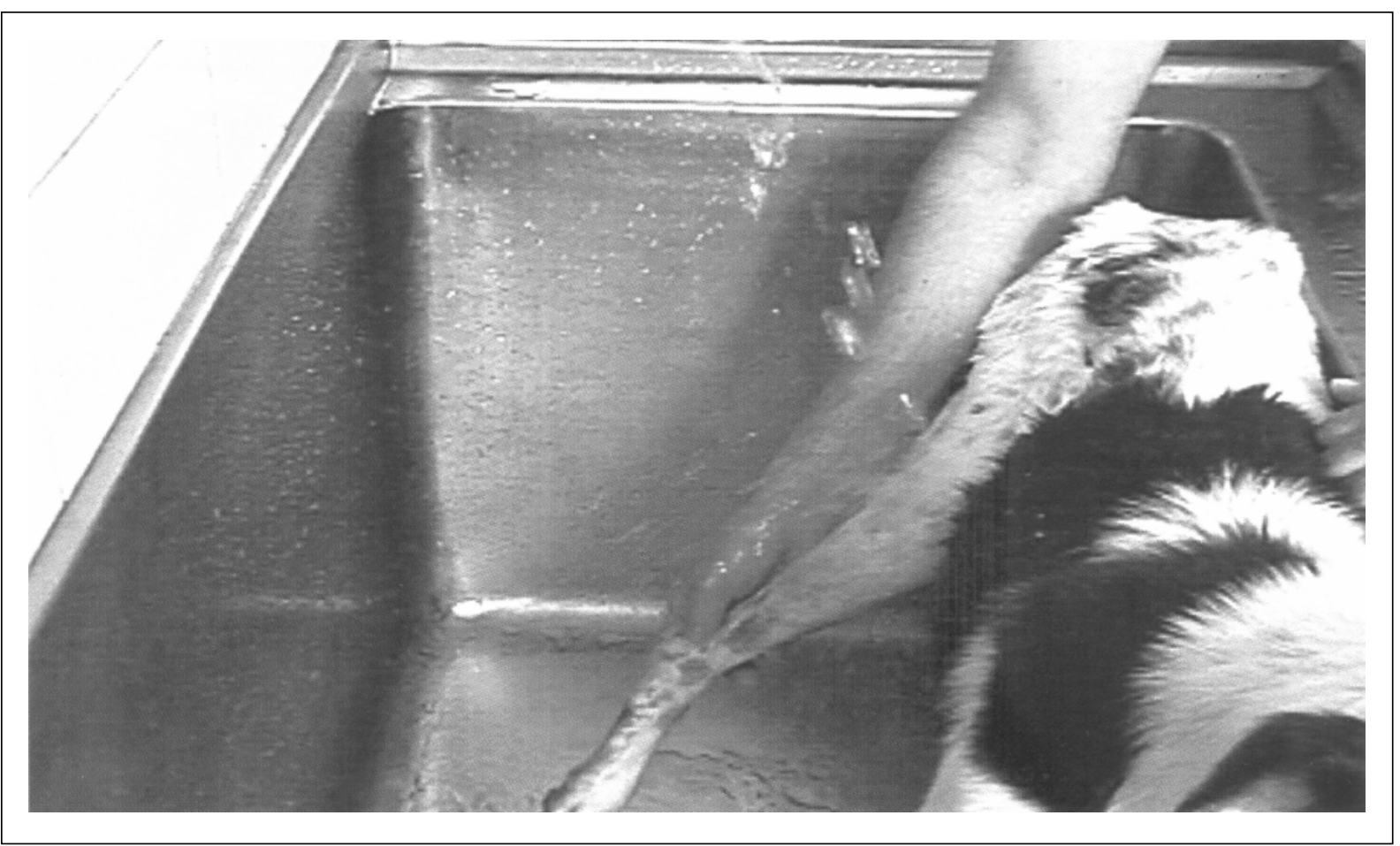

Figura 1 - Terapia física em cão submetido à artroplastia do joelho seguida de imobilização rígida temporária da articulação do joelho. Nota-se o emprego da hidroterapia na forma de ducha simultaneamente ao alongamento passivo da articulação do joelho.

No período pré-operatório, após a remoção da imobilização externa (30 dias) e 90 dias depois da cirurgia articular, foram realizadas mensurações da circunferência da coxa, com auxílio de uma fita métrica, e da amplitude de flexão e extensão, com um goniômetro plásticof.

Após a remoção do fixador externo, a marcha dos animais dos grupos I e II foi avaliada clinicamente antes da terapia física (grupo I), por um mesmo observador, durante 60 dias consecutivos, sendo estimada mediante cinco graus: I - o paciente não usa e nem apóia o membro operado operado; II - uso e apoio infreqüentes do membro durante estação e ao caminhar, não sustentando o peso no membro afetado, elevandoo ao correr; III - uso claudicante do membro na estação e ao caminhar, sustentação parcial do membro, elevando o membro ao correr; IV - caminha sem claudicar e posiciona-se normalmente em estação, claudicando ao correr, sem elevar o membro e V - uso funcional do membro (TUDURY \& RAISER, 1985).

Para avaliação dos resultados, aplicou-se análise de variância (ANOVA) de uma via, seguida de teste de comparações múltiplas de Duncan. Todos os resultados foram indicados pela média \pm Erro Padrão da Média (EPM).

\section{RESULTADOS E DISCUSSÃO}

Quanto à avaliação clínica da marcha, podese perceber que não houve diferença significativa entre os grupos tratado e controle quando estes permaneciam em grau I. Isto se deve ao fato de a terapia física não influenciar inicialmente $\mathrm{o}$ apoio funcional do membro ao solo, corroborando com CARVALHO (2001), o qual afirmou que a recuperação inicia entre três e cinco dias após o início de um programa de reabilitação. Já com relação aos graus II e III de claudicação, observou-se que os animais do grupo controle permaneceram por um período maior de tempo em cada um destes graus quando comparados aos cães do grupo tratado. Adicionalmente, todos os cães $(n=4)$ do grupo tratado atingiram o grau $\mathrm{V}$, decorrido 90 dias de pós-operatório, enquanto que somente um paciente do grupo controle chegou a esse grau. Isto demonstra que a terapia física influenciou positivamente, de forma evolutiva em relação ao tempo, o retorno funcional do membro, principalmente por interromper o espasmo muscular (SUTTON, 2004), que fora evidenciado em todos os animais deste experimento após a remoção do fixador externo.

A hidroterapia empregada com água na temperatura de $37^{\circ} \mathrm{C}$ por um período de 15 minutos, 


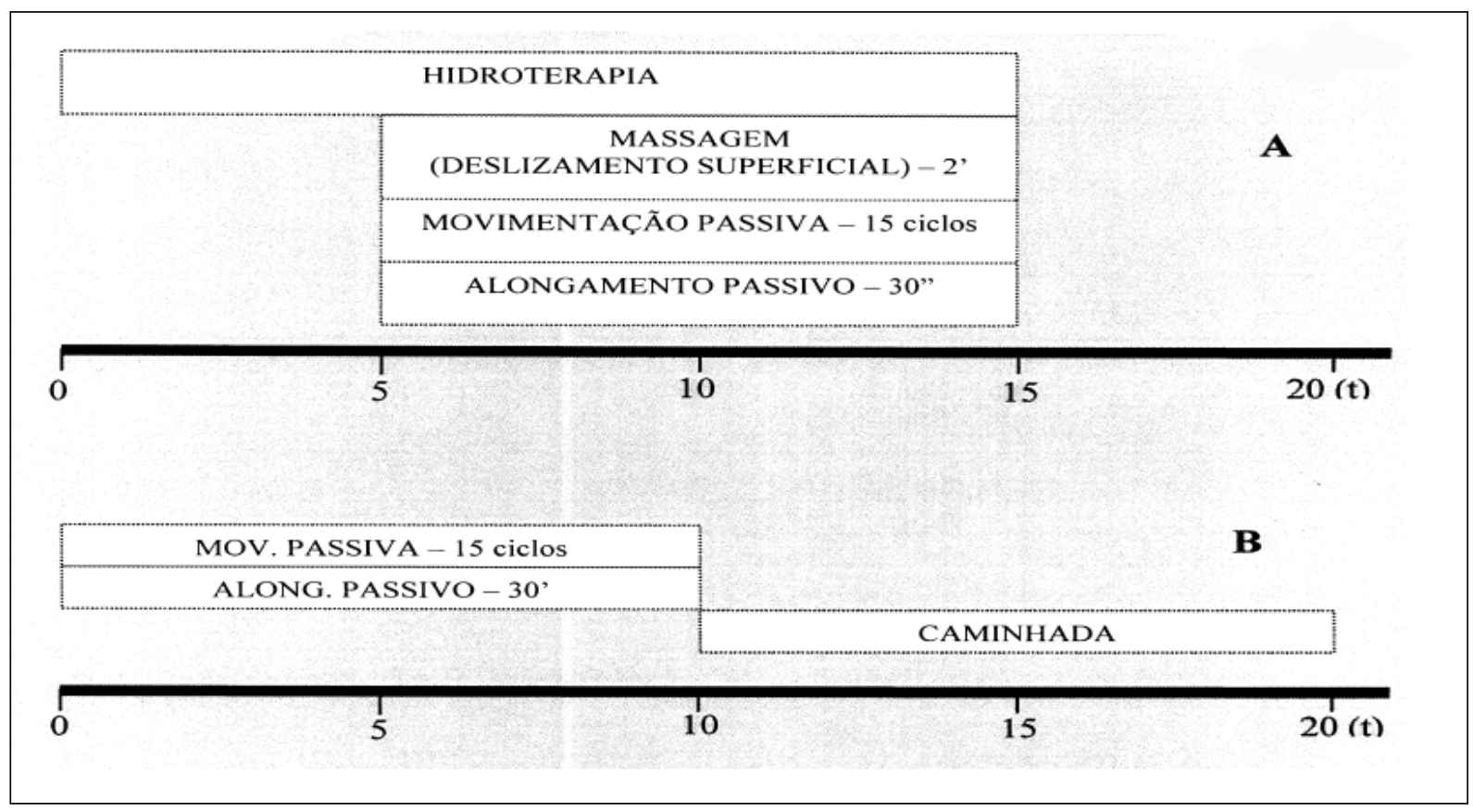

Figura 2 - Representação esquemática do protocolo de terapia física de acordo com o tempo (t), em minutos, empregado nos pacientes do grupo I, 24 horas após a remoção do aparelho de fixação externa (A) e após as sessões de hidroterapia (B). Nota-se em A que a hidroterapia foi empregada de forma concomitante e os exercícios terapêuticos de forma alternada entre si, totalizando um tempo de 35 minutos.

durante 15 dias, teve o intuito de promover o aquecimento superficial da musculatura da coxa. HEINRICHS et al. (2004) explicaram que este efeito causa a inibição da transmissão da dor (via sistema de comporta), o relaxamento muscular e o aumento da extensibilidade dos tendões, dos ligamentos e da cápsula articular, facilitando o emprego de outras modalidades como o massageamento manual por deslizamento superficial, a movimentação passiva da articulação e o alongamento passivo, sem o risco de ocasionar contraturas musculares desencadeadas pela dor, conforme salientaram TAYLOR (1992) e MILLIS \& LEVINE (1997). Isto também foi constatado por MAZZANTI et al. (2004), que utilizaram previamente o aquecimento superficial na musculatura da coxa por duchas de água a $37^{\circ} \mathrm{C}$ e, ao realizarem a movimentação passiva, notaram o aumento da amplitude articular em extensão e a flexão da articulação sem manifestação clínica de dor pelo paciente. KITCHEN (2003) ainda citou que o aquecimento superficial reduz a resistência articular ao movimento por mudanças na viscosidade do líquido sinovial. Logo, recomenda-se o prévio aquecimento superficial das estruturas envolvidas na terapia física antes de iniciarem-se os exercícios terapêuticos a fim de se obter um máximo aproveitamento, sem riscos de ocasionar lesões iatrogênicas.
A movimentação passiva da articulação (MPA) do joelho operado diminuiu a rigidez articular provocada pela imobilização rígida, decorridos em média cinco dias de tratamento, o que está em acordo com TAYLOR (1992), DIGÓN (2000), CLARK \& McLAUGHLIN (2001), CONZEMIUS (2004) e MILLIS et al. (2004). Esses autores citaram que a MAP reduz a aderência tecidual, promove a movimentação normal da articulação por meio da reeducação muscular e previne as contraturas musculares e de cápsula articular. Adicionalmente, a MPA estimula mecanoreceptores existentes na articulação do joelho, auxiliando na facilitação neuromuscular proprioceptiva por meio da ativação dos fusos musculares e do órgão tendinoso de Golgi, promovendo o relaxamento muscular e o aumento da amplitude de movimento, conforme salientaram PRENTICE (2002); AMARAL (2006).

O método de alongamento passivo realizado durante e após aplicação da hidroterapia proporcionou o relaxamento da musculatura da coxa, que se encontrava espástica, e da articulação com limitação de sua amplitude em decorrência da imobilização articular temporária, resultados também encontrados por STARRING (1988). A técnica de alongamento deve ser realizada em conjunto com os exercícios de movimentação passiva da articulação para melhorar a flexibilidade das articulações, a extensibilidade dos 
tecidos periarticulares e dos tendões e a elasticidade muscular.

O apoio do membro operado em solos irregulares foi empregado seguindo as recomendações de HAMILTON et al. (2004), visando a promover estimulação dos receptores proprioceptivos situados nas articulações e nos tendões, exigindo do animal mecanismos "compensatórios" (ex.: equilíbrio e contração muscular) os quais, segundo PRENCTICE (2002), permitem uma adequada orientação da posição do membro ao solo. Para AMARAL (2006) o uso de exercícios para reeducação proprioceptiva por meio de estímulos tem como finalidade reprogramar a função do movimento e obter efeitos cinestésicos.

Quanto à avaliação da amplitude articular em extensão, pode-se verificar que os animais submetidos a terapia física (grupo I) obtiveram melhor recuperação $(\mathrm{P}<0,01)$ e atingiram os valores iguais aos mensurados no pré-operatório, decorridos os 90 dias de evolução. As técnicas de alongamento passivo e de calor superficial foram as modalidades empregadas que mais contribuíram para este resultado, pois, conforme PRENCTICE (2002), estimulam receptores dos fusos musculares e tendinosos por meio do mecanismo de inibições autogênica e recíproca, além de, segundo STARRING (1988), promoverem aumento da amplitude de movimento.

Quanto à perimetria da coxa, foi notado que os animais dos grupos I e II não recuperaram os valores obtidos no pré-operatório, o que demonstra que o protocolo empregado não promoveu o ganho de massa muscular. Isso traz como desvantagem um aumento na susceptibilidade do membro em sofrer algum tipo de lesão articular, já que a musculatura atrofiada não promoveria a sua estabilização necessária. Logo, recomenda-se avaliar a inclusão no protocolo de reabilitação de um método, como a estimulação elétrica neuromuscular, para auxiliar no ganho de massa muscular, conforme citaram CLARK \& McLAUGHLIN (2001).

\section{CONCLUSÃO}

Com base nos resultados obtidos, pode-se concluir que o protocolo de terapia física empregado neste experimento influencia positivamente no retorno funcional do membro de cães submetidos à artroplastia do joelho seguida de imobilização, por um período de 30 dias.

\section{FONTES DE AQUISIÇÃO}

apamoato de pirantel - Petzi plus. Vetbrands. Porto Alegre, RS. ${ }^{\mathrm{b}}$ Flunixin meglumine - Banamine. Schering-Plough. Rio de Janeiro, RJ.
${ }^{\mathrm{c}}$ Cloridrato de tramadol - Tramadol. Eurofarma. São Paulo, SP. ${ }^{\text {d} S u l f a t o ~ d e ~ m o r f i n a ~-~ D i m o r f . ~ C r i s t a l i a ~ d o ~ B r a s i l . ~ S a ̃ o ~ P a u l o, ~ S P . ~}$ ePropofol - Diprivan. ICI Wellcome, São Paulo - SP.

${ }_{\mathrm{f}}^{\mathrm{f}}$ oniômetro universal de plástico - Carci. São Paulo - SP

\section{AGRADECIMENTO}

Ao Conselho Nacional de Desenvolvimento Científico e Tecnológico (CNPq), pelos recursos de adicional de bancada concedidos à Alceu Gaspar Raiser, pesquisador 1B, processo 550866/2002-7.

\section{REFERÊNCIAS}

AMARAL, A.B. Cinesioterapia. In: MIKAIL, S.; PEDRO, C.R. Fisioterapia veterinária. São Paulo: Manole, 2006. Cap.6, p.50-62.

CARVALHO, C.M.M. Efeitos da imobilização e do exercício físico em algumas propriedades mecânicas do músculo esquelético. 2001. 61f. Dissertação (Mestrado em Bioengenharia da EESC/FMRP/IQSC) - Universidade de São Paulo.

CLARK, B.; McLAUGHLIN, R. M. Physical rehabilitation in small-animal orthopedic patients. Veterinary Medicine, Mississipi, v.96, n.3, p.234-246, 2001.

CONZEMIUS, M. Physical therapy for stifle injury. In: AMERICAN COLLEGE OF VETERINARY SURGEONS VETERINARY SYMPOSIUM, THE SURGICAL SUMMIT, 2004, Detroit, EUA. Procedings... Detroit: Omnipress, 2004. p.373-375. CD-ROM.

DIGÓN, N. Fisioterapia y rehabilitación en neurología. In: PELLEGRINO, F. et al. Síndromes neurológicos en perros y gatos. Colombia: Inter-medica, 2000. Cap.25, p.349-358.

HAMILTON, S. et al. Therapeutic exercises. In: MILLIS, D.L et al. Canine rehabilitation physical therapy. Philadelphia: Saunders, 2004. Cap.14, p.244-263.

HEINRICHS, K. Superficial thermal modalities. In: MILLIS, D.L. et al. Canine rehabilitation physical therapy. Philadelphia: Saunders, 2004. Cap.16, p.277-288.

KITCHEN, S. Eletroterapia. Prática baseada em evidências. 11.ed. São Paulo: Manole, 2003. 348p.

MARSOLAIS, G.S. et al. Effects of postoperative rehabilitation on limb function after cranial cruciate ligament repair in dogs. Journal of American Veterinary Medical Association, Chicago, v.220, n.9, p.1325-1330, 2002.

MAZZANTI, A., et al. Homoimplnate ortotópico conservado, associado á terapia soft laser na reparação tenopaterlar em cão. Ciência Rural, Santa Maria, v.34, n.4, p.429-437, 2004.

MILLIS, D. L.; LEVINE, D. The role of exercise and physical modalities in the treatment of osteoarthritis. Veterinary Clinics of North America: Small Animal Practice, Philadelphia, v.27, n.4, p.913-930, 1997. 
MILLIS, D.L. et al. Range-of-motion and stretching exercises. In: MILLIS, D.L. et al. Canine rehabilitation \& physical therapy. Philadelphia: Saunders, 2004. Cap.13, p.228-243.

PRENTICE, W.E. Técnicas de facilitação neuromuscular proprioceptiva na reabilitação. In: Técnicas de reabilitação em medicina esportiva. 3.ed. São Paulo: Manole, 2002. Cap.13, p.198-215.

STARRING, D.T.,et al. Comparison of cyclic and sustained passive stretching using a mechanical device to increase resting length of hamstring muscles. Physical Therapy, Washington, v.68, n.3, p.314-320, 1988.
SUTTON, A. Massage. In: MILLIS, D.L. et al. Canine rehabilitation \& physical therapy. Colorado: Saunders, 2004. Cap.18, p.303-323.

TAYLOR, R.A. Postsurgical physical therapy: the missing link. Compendium on Continuing Education for the Practicing Veterinarian, Toronto, v.14, n.12, p.1583-1593, 1992.

TUDURY, E.A.; RAISER, A.G. Redução de fraturas distais de fêmur em cães, empregando pinos de Steinmann em substituição aos de Rush. Revista do Centro de Ciências Rurais, Santa Maria, v.15, n.2, p.141-155, 1985. 